\title{
Development of cable-in-conduit conductor for ITER CS in Japan
}

\author{
H. Kajitani ${ }^{1} \cdot$ T. Hemmi $^{1} \cdot$ T. Suwa $^{1} \cdot$ Y. Takahashi $^{1} \cdot$ K. Matsui ${ }^{1} \cdot$ N. Koizumi $^{1}$ \\ (c) Springer Nature Switzerland AG 2019
}

\begin{abstract}
The National Institutes for Quantum and Radiological Science and Technology has the responsibility to develop a cablein-conduit conductor (CICC) for the ITER central solenoid (CS). Qualification tests of CICCs fabricated in the initial development stage were carried out at the SULTAN test facility; the superconducting performance $\left(T_{\mathrm{cS}}=\right.$ current-sharing temperature) was found to be degraded by the repeated cyclic loading that simulates realistic ITER operating conditions. From destructive examination and neutron diffraction tests, this degradation appears to result from bending strain on the strands generated by electromagnetic forces. In response, the cabling of the $\mathrm{CICC}$ was optimized by shortening the twist pitch to make it stiffer against electromagnetic forces. No $T_{\mathrm{cs}}$ degradation of the optimized $\mathrm{CICC}$ was seen in the subsequent SULTAN test; further, a CS insert (CSI) test was performed at the CS model coil test facility, which included hoop strain for a more realistic simulation of ITER conditions. Good performance was also achieved in the CSI test.
\end{abstract}

Keywords ITER · Cable-in-conduit conductor · Superconducting magnet system · Central solenoid

\section{Introduction}

The International Thermonuclear Experimental Reactor (ITER) is an international project undertaken by China (CN), Europe (EU), India (IN), Korea (KO), the Russian Federation (RF), the United States (US), and Japan (JA) [1]; these members are responsible for the design and fabrication of the major components to be assembled into the ITER facility. An overview of ITER is shown in Fig. 1; plasma confinement in the device is based on a superconducting magnet system. All ITER members except IN contribute to the development. The ITER magnet system is the largest unified superconducting magnet system ever built in the world.

The superconducting magnet system $[2,3]$ consists of four different types of coils. These are 18 toroidal field (TF) coils, 6 poloidal field (PF) coils, 18 correction coils (CC), and 6 central solenoid (CS) modules, as shown in Fig. 2. These coils rely on cable-in-conduit conductors (CICCS) [4], which contain superconducting strands twisted in multiple stages in a stainless steel conduit. The conductors in the TF and CS coils consist of $\mathrm{Nb}_{3} \mathrm{Sn}$ strands, while the PF and CC conductors consist of Nb-Ti strands. These conductors are cooled by cryogenic fluids and operated below the current-sharing temperature $\left(T_{\mathrm{cs}}\right)$.

The National Institutes for Quantum and Radiological Science and Technology (QST), acting as Japan's domestic agency in ITER, has responsibility to develop the CS conductor $[5,6]$. There are 49 conductors, each having the length of several hundred meters, which are to be produced for the CS. The operating scenario for the CS is pulsed operation that induces 15 MA of plasma, with 30,000 repetitions and a burn duration of $400 \mathrm{~s}$ [7]; the CS conductor must therefore survive severe repeated cycles of electromagnetic force (EM). A requirement of the CS conductor is no degradation of $T_{\text {cs }}$ from the EM cycles.

In 2010 and 2011, qualification tests of the CS conductor initially developed were performed, showing unexpected degradation of $T_{\text {cs }}$ in the EM cycles. Investigations were undertaken to understand this degradation $[8,9]$; one of the most effective techniques was neutron diffraction

H. Kajitani, kajitani.hideki@qst.go.jp| ${ }^{1}$ National Institutes for Quantum and Radiological Science and Technology (QST), 801-1, Mukouyama, Naka-shi, Ibaraki 311-0193, Japan.

SN Applied Sciences (2019) 1:182 | https://doi.org/10.1007/s42452-019-0194-0

Received: 24 May 2018 / Accepted: 21 January 2019 / Published online: 28 January 2019 


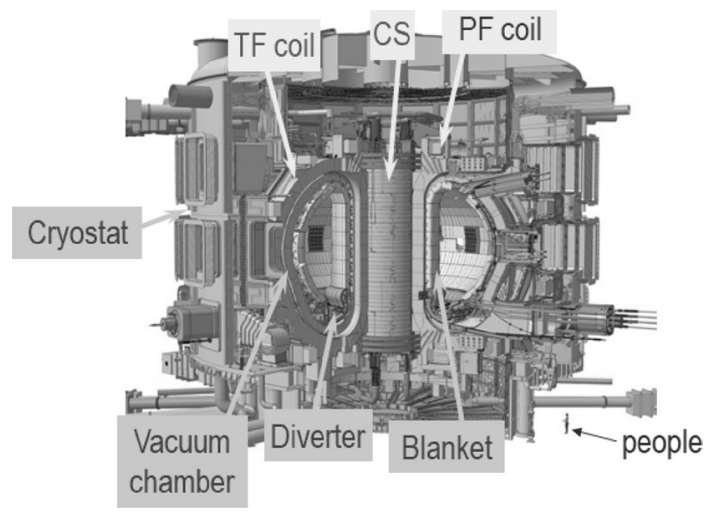

Fig. 1 Overview of ITER. CS designates the central solenoid; TF toroidal field, $P F$ poloidal field

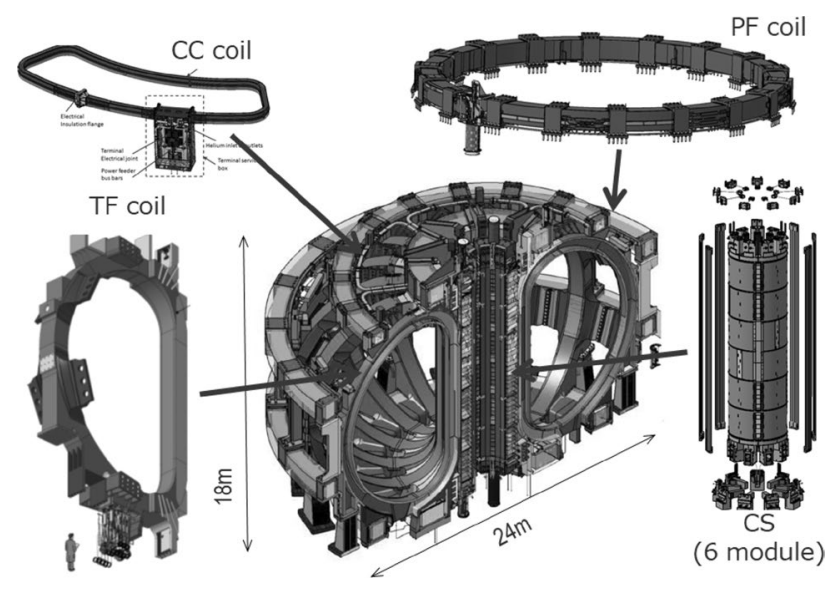

Fig. 2 ITER superconducting magnet system (TF, PF, CC coils, and CS)

analysis. This analysis clearly showed strand deformation [10] as the cause of the $T_{\mathrm{cs}}$ degradation; consequently, the authors decided to optimize the conductor design to prevent this deformation. The status of this work is described in this paper.

To re-design the conductor [11-13], the twist pitch of the cable was shortened. It was expected that a shorter twist pitch configuration would reduce the strand deformation under EM cycles; however, this optimization produced another problem: dented strands during the cabling process. To overcome this issue, QST improved the cabling process by applying empirical criteria to the dented strand [14]; an overview is presented in this paper.

In 2012, a qualification test of the optimized conductor with a shorter twist pitch was performed and showed no degradation of $T_{\text {cs }}$ with EM cycles [15]. With this success, series production of the CS conductors could begin, and in parallel, to confirm the performance of the optimized short twist pitch conductor under conditions which more precisely duplicate the ITER CS operation, a central solenoid insert (CSI) was tested in 2015. The results satisfied all the CS requirements with a sufficient margin for $T_{\text {cs }}[16]$. The status is also described in this paper.

\section{ITER CS conductor}

The CS consists of 6 modules designated CS1U, CS1L, $\mathrm{CS} 2 \mathrm{U}, \mathrm{CS} 2 \mathrm{~L}, \mathrm{CS} 3 \mathrm{U}$, and CS3L, as shown in Fig. 3. Each module has 40 layers of 6 hexa-pancake and 1 quadrapancake. The hexa-pancake and quadra-pancake consist of $918 \mathrm{~m}$ and $613 \mathrm{~m} \mathrm{CIC}$ conductor, respectively. Thus, a total of $49 \mathrm{CIC}$ conductors are required for six modules plus one spare.

The CS is pulse-operated to produce $15 \mathrm{MA}$ of plasma in the ITER scenario. Details of the scenario are shown in [7]. In this operation, the charge and discharge are repeated up to 30,000 cycles, and thus, the CS conductor is subjected to 60,000 repeated EM cycles. In this scenario, the conductor current is ramped up to $45 \mathrm{kA}$ in a maximum field of $13 \mathrm{~T}$. To accommodate this combination of high current and high magnetic field, the CS conductor consists of $576 \mathrm{Nb}_{3} \mathrm{Sn}$ and 288 copper strands, twisted in several stages and contained in a stainless steel conduit [7], as shown in Fig. 4. The conductor is cooled and should be operated below its current-sharing temperature, $T_{\text {cs }}$. Thus, the value of $T_{c s}$ should remain above the operating temperature under repeated EM cycles. In the operation, there are two main critical conditions: One is the start-ofdischarge (SOD), and the other is the end-of-burn (EOB) [7]. The SOD, with $40 \mathrm{kA}$ of conductor current and $13 \mathrm{~T}$ of maximum field, presents the most severe conditions, that is, the smallest temperature margin; in comparison, the maximum EM force is applied during the EOB. Therefore,

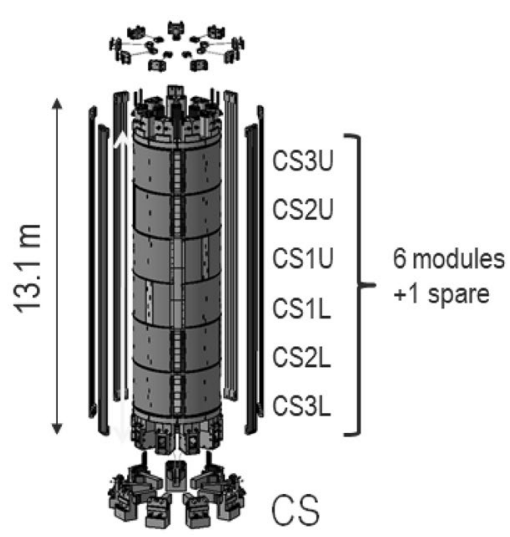

- $6 \times$ Hexa-pancake

- $1 \times$ Quadra-pancake

- Total 40 layer

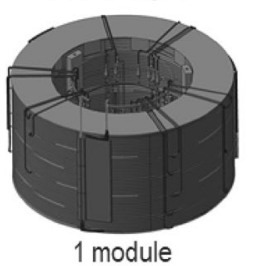

Fig. 3 Overview of central solenoid (6 modules). Each module contains 40 pancake layers 


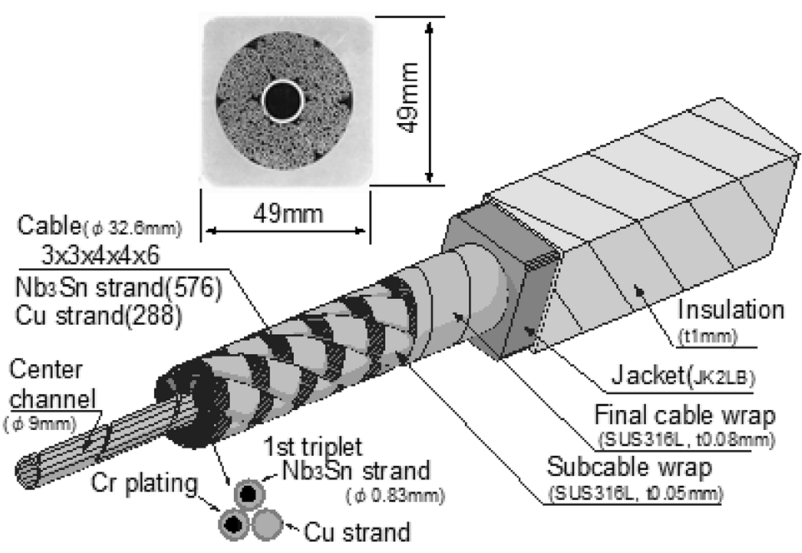

Fig. 4 ITER CS conductor center channel is for cooling; first twisted strand (triplet) contains two $\mathrm{Nb}_{3} \mathrm{Sn}$ strands and one $\mathrm{Cu}$ strand; final stage of 6 strands shows the wrapping on each strand. In total, there are $576 \mathrm{Nb}_{3} \mathrm{Sn}$ strands and 288 copper strands

the constraint on $T_{\mathrm{cS}}$ is defined by the SOD conditions; the limiting value for $T_{\mathrm{cs}}$ is $5.2 \mathrm{~K}$.

\section{Initial design of the CS conductor}

The major parameters of the initial CS conductor are listed in Table 1; this design was based on previous reports [17, 18]. $\mathrm{Nb}_{3} \mathrm{Sn}$ and $\mathrm{Cu}$ strands were twisted in five stages with $45,85,145,250$, and $450 \mathrm{~mm}$ pitch, with a center channel, and then inserted into a JK2LB $49 \mathrm{~mm}$ square stainless steel conduit. In the initial stage of the development, the qualification test was performed using the SULTAN test facility and will be denoted the SULTAN test. Its purpose was to determine whether the conductor satisfies the required $T_{\text {cs }}$ through a number of EM cycles.

In the SULTAN test, two straight conductor samples of length about $3.5 \mathrm{~m}$ are positioned as shown in the test facility, which applies an external magnetic field (Fig. 5) [19]. The SULTAN test facility is the only way to confirm performance of ITER scale conductor. However, the peak external field is limited to $10.85 \mathrm{~T}$, which corresponds to about $11.5 \mathrm{~T}$ of maximum field during conductor current

Table 1 Major parameters of the CS conductor initial design

\begin{tabular}{ll}
\hline Conductor & \\
\hline Cabling layout & $(2 \mathrm{SC}+1 \mathrm{Cu}) \times 3 \times 4 \times 4 \times 6$ \\
Twist pitch & $45 / 85 / 145 / 250 / 450 \mathrm{~mm}$ \\
Jacket material & $\mathrm{JK} 2 \mathrm{LB}$ \\
Inner cable diameter & $32.6 \mathrm{~mm}$ \\
Outer dimension & $49 \mathrm{~mm} \times 49 \mathrm{~mm}$ \\
Void fraction & $34.3 \%$ \\
\hline
\end{tabular}

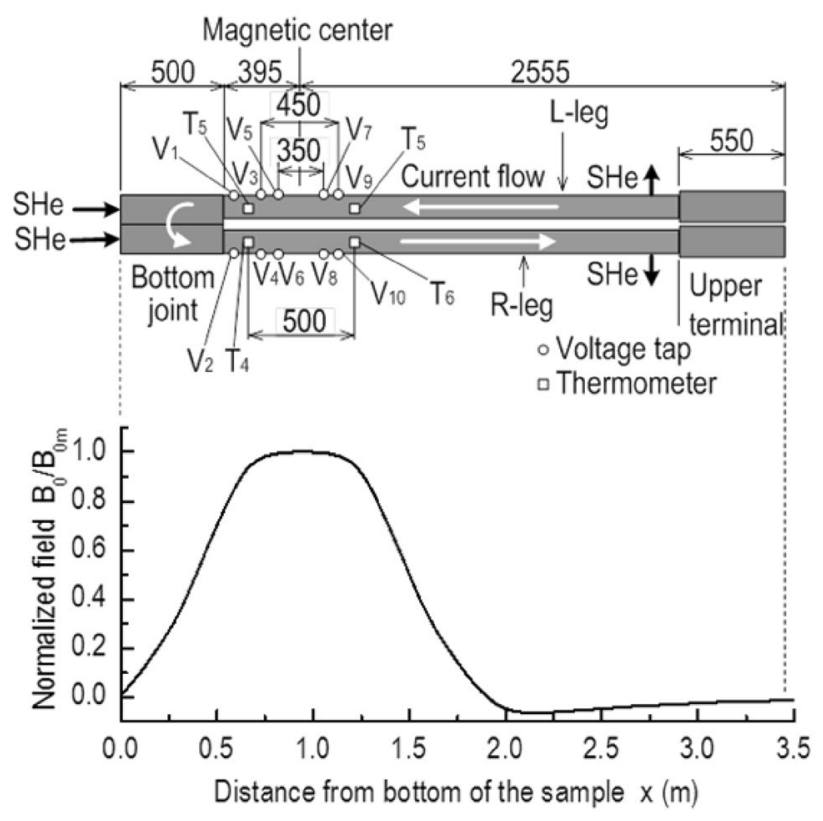

Distribution of magnetic field from the SULTAN coil system

Fig. 5 Overview of SULTAN test and the conductor sample

flow. Therefore, the current chosen for the $T_{\mathrm{cs}}$ measurements was $45 \mathrm{kA}$, which reproduces the EM force experienced during the SOD condition (i.e., SOD condition: 40 $\mathrm{kA} \times 13 \mathrm{~T} \simeq$ SULTAN condition: $45 \mathrm{kA} \times 11.5 \mathrm{~T}$ ), while $\mathrm{EM}$ cycle is done by $48.8 \mathrm{kA}$ of sample current (EOB condition) [4]. As the external field in the SULTAN test condition is different from that during SOD, the $T_{\text {cS }}$ criterion was adjusted to $6.5 \mathrm{~K}$ for the test.

To measure the current-sharing temperature $T_{C S^{\prime}}$ the voltage of the sample was monitored as its temperature was increased, while maintaining the test conditions of $45 \mathrm{kA}$ and $11.5 \mathrm{~T}$. $T_{\mathrm{cs}}$ is defined as the temperature when the voltage reaches $10 \mu \mathrm{V} / \mathrm{m}$. The $T_{\text {cs }}$ measurement was repeated through the test, allowing the $T_{\mathrm{cs}}$ dependence on number of EM cycles to be determined (Fig. 6). $T_{\text {cs }}$ decreases linearly with the number of EM cycles and is extrapolated to fall below the criterion of $6.5 \mathrm{~K}$ at around 12,000 cycles. Thus, the initial conductor design is clearly not appropriate for the CS conductor.

\section{Consideration of the degradation}

To investigate the SULTAN test results seen in Fig. 6, which shows an unexpected level of $T_{\mathrm{cs}}$ degradation with EM cycles, a destructive examination (DE) was done on the sample tested. A visual inspection of a section of cable surface was carried out to investigate the effects of the large EM forces applied; the observations were specifically 


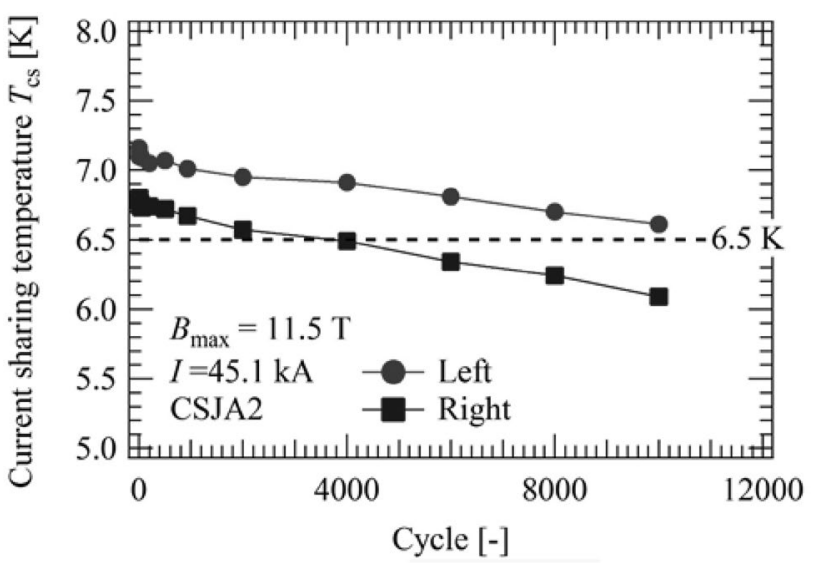

Fig. 6 Current-sharing temperature $T_{\text {cs }}$ for the initial conductor design, as a function of EM cycles

directed at the high-load zone (HLZ) and the low-load zone (LLZ). The inspection showed that strands in the LLZ exhibited the most bending (Fig. 7). Because the direction of the bent strand did not correspond to that of the EM loading, another cause was sought; the original assumption had been that strand bending was only caused by EM loading in the HLZ $[20,21]$. Thus, the observed phenomenon required a more complex explanation.

Researchers have tried to understand this unexpected strand deformation in the LLZ $[9,22]$; one mechanism was assumed: strand buckling. In this mechanism, thermal compressive forces originally acted on strands inside the conduit as a result of differences between the thermal

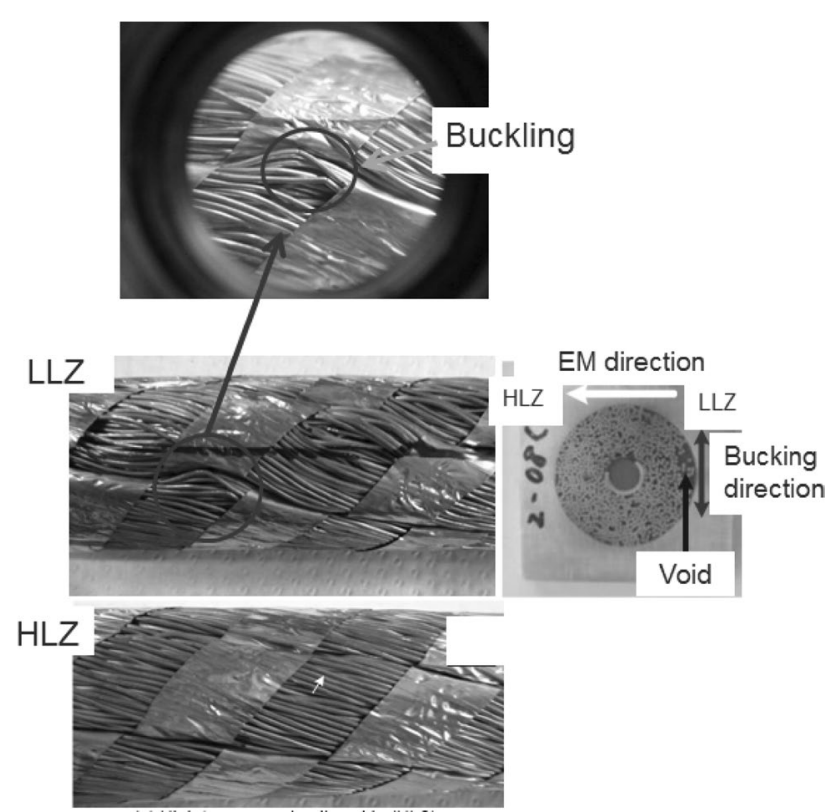

Fig. 7 Cable surface in the LLZ and HLZ observed in destructive examination of the SULTAN test sample contraction properties of materials in the conductor, operating during the heat treatment and cool-down process. On the other hand, a large void was generated in the LLZ because EM loading pushed strands forward toward the HLZ. Since the large void allows strands to move easily, strands were compressed and then buckled by the thermal compressive forces, and as a result, strand buckling occurs in the LLZ [23].

To study the bent strand condition more quantitatively, various approaches were taken $[9,22,23]$. One of the most sophisticated studies used neutron diffraction analysis [10], which accurately evaluates strains in the strands inside the conductor. Figure 8 shows schematically the response of a neutron diffraction profile for the cases of axial or bending strain. If axial strain occurs, the diffraction peaks are shifted, while if bending strain occurs, the diffraction profile is broadened.

The neutron diffraction analysis was performed for SULTAN test samples from the HLZ, the LLZ, and a low-field zone (LFZ) where the external field is almost zero. Since the LFZ is exposed to a sufficiently small electromagnetic force, it is assumed there is no degradation. The result is shown in Fig. 9. The diffraction profile from the LLZ is much broader than the other profiles. This clearly shows that strands in the LLZ bent the most severely. Since $\mathrm{Nb}_{3} \mathrm{Sn}$ strands are very sensitive to strain, it was concluded that the main cause of conductor degradation shown in Fig. 6 was strand deformation such as buckling and/or bending in the LLZ.

\section{Optimized conductor design}

To prevent the strand deformations in the LLZ mentioned in the last section, research and development on the cable configuration was undertaken [11-13]. The main approach chosen for optimization was to shorten the twist pitch of the cable to $20,45,80,150$, and $450 \mathrm{~mm}$ in the stages, as shown in Fig. 10. It was expected that the short twist pitch (STP) configuration would reduce the strand deformation
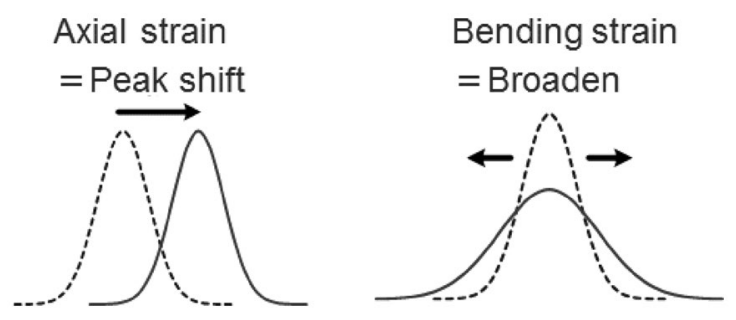

Fig. 8 Response of a neutron diffraction profile for axial or bending strain 


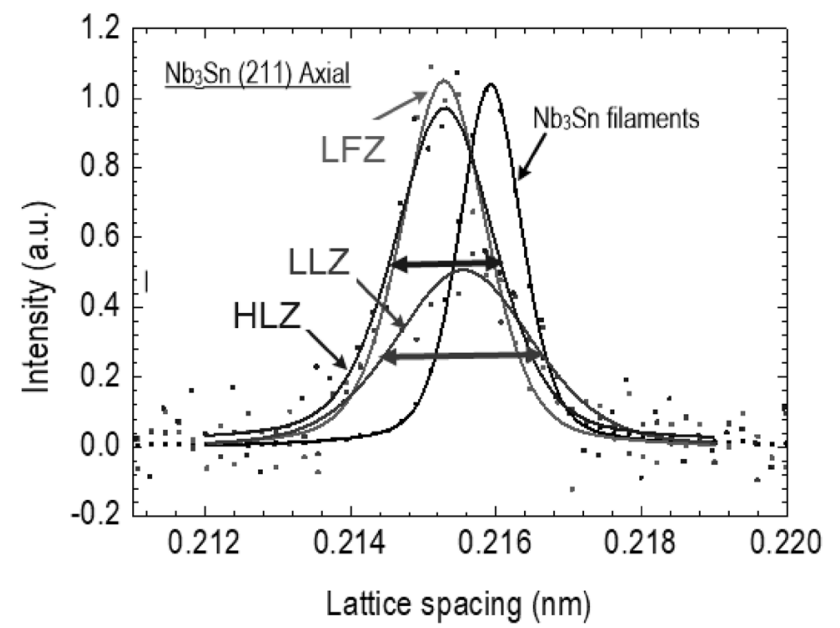

Fig. 9 Neutron diffraction analysis for high-load zone (HLZ), lowload zone (LLZ), and low-field zone (LFZ) SULTAN test samples

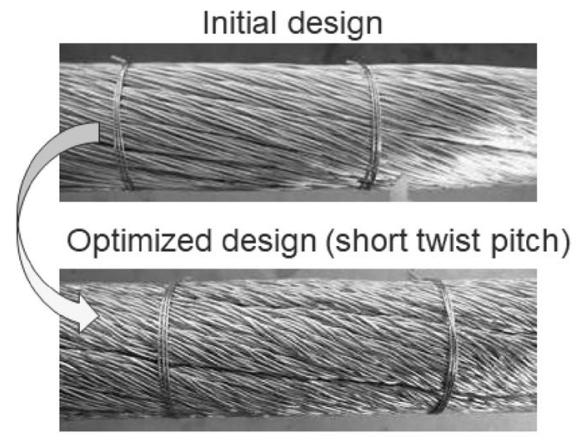

\begin{tabular}{|c|c|c|c|}
\hline & & Initial design & Optimized design \\
\hline \multirow{5}{*}{ Twist pitch } & $1^{\text {st }}$ & $45 \pm 5 \mathrm{~mm}$ & $\Rightarrow \quad 20 \pm 5 \mathrm{~mm}$ \\
\hline & $2^{\text {nd }}$ & $85 \pm 10 \mathrm{~mm}$ & $45 \pm 5 \mathrm{~mm}$ \\
\hline & $3^{\text {rd }}$ & $145 \pm 10 \mathrm{~mm}$ & $\Rightarrow 80 \pm 10 \mathrm{~mm}$ \\
\hline & $4^{\text {th }}$ & $250 \pm 15 \mathrm{~mm}$ & $\Rightarrow 150 \pm 15 \mathrm{~mm}$ \\
\hline & $5^{\text {th }}$ & \multicolumn{2}{|c|}{$450 \pm 20 \mathrm{~mm}$} \\
\hline \multicolumn{2}{|c|}{ Void fraction } & $34.3 \%$ & $31.9 \%$ \\
\hline
\end{tabular}

Fig. 10 Optimized short twist pitch conductor design

under EM cycles (seen in Fig. 7) because each strand is more tightly fixed inside a cable with a lower void fraction.

However, this optimization approach produced another problem for the cable production process. Destructive examination of the modified (i.e., STP) conductor sample revealed severe strand cross-sectional deformation inside the cable, as shown in Fig. 11 [14]. This deformation occurred during the cable manufacturing process, as a result of each strand being more tightly twisted and compacted. To assess the influence of this deformation on strand performance, critical current $\left(I_{c}\right)$ measurements on dented strands were performed (Fig. 12). From these measurements, $I_{c}$ can be kept to $95 \%$ of its value if the dents are smaller than $0.21 \mathrm{~mm}$; this

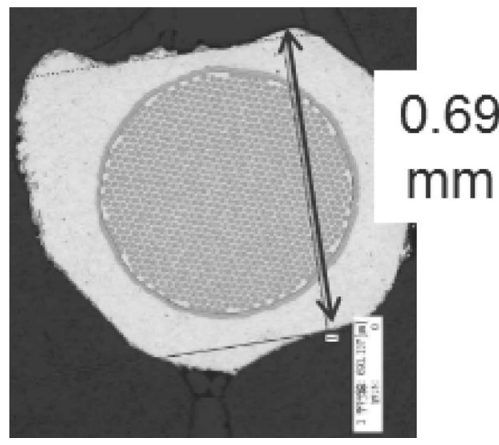

Fig. 11 Strand deformation during the cabling process

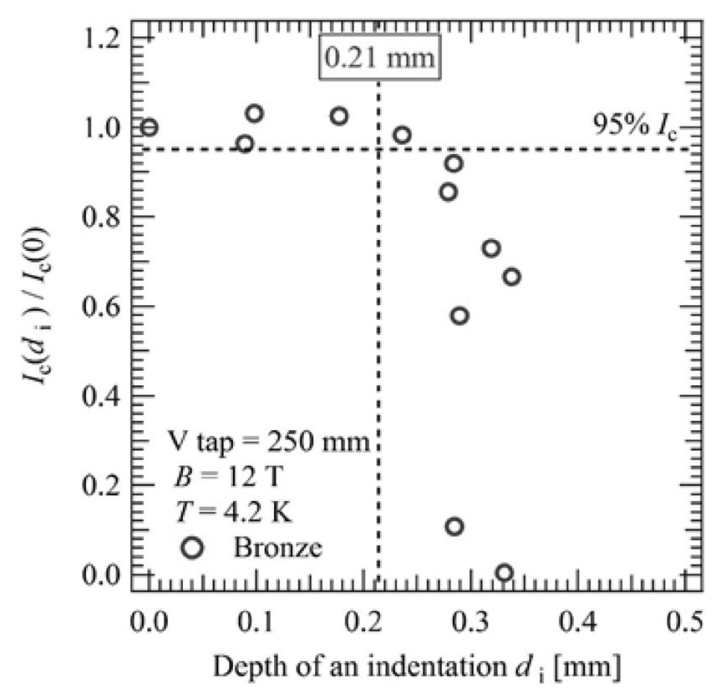

Fig. 12 Results of $I_{c}$ measurement on dented strands. The horizontal axis is the depth of indentation, and the vertical axis shows $I_{c}$ normalized to the undented value

new result gave the authors an empirical criterion for cable production. Based on this observation, the parameters of the cabling machine can be optimized so that harmful deformation of strands is avoided.

To confirm this effect in the STP-modified conductor, the SULTAN test was performed under the same conditions as in Fig. 6, with the results shown in Fig. 13 [13]. No degradation was observed through the same number of EM cycles, and it is concluded that this STP conductor design is appropriate for the CS conductor. Following the success of this development, series production of CS conductors was started.

\section{CS insert test}

Following the success of the SULTAN test with the optimized STP conductor, the series production of CS conductors could be started, as mentioned above. In 


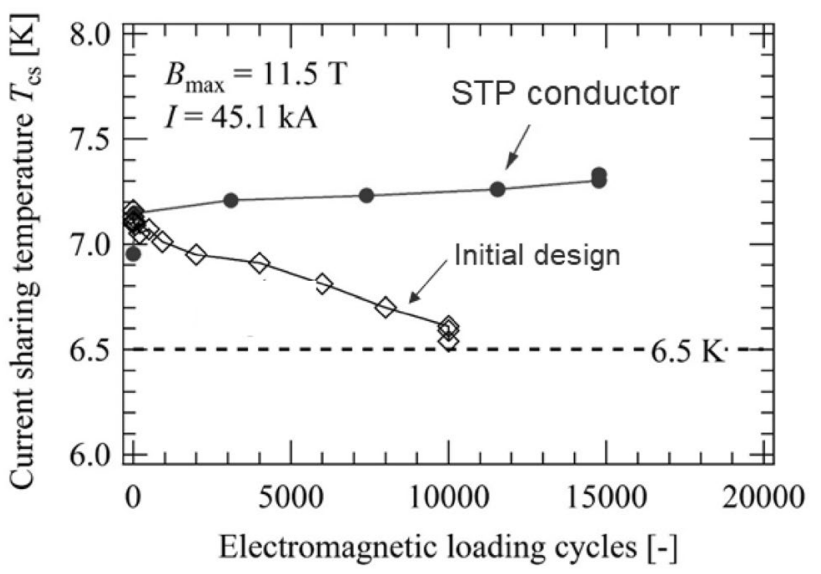

Fig. 13 Measurement results of $T_{\text {cs }}$ as a function of EM cycles in the optimized short twist pitch conductor

parallel, to finally check the performance of the STP conductor under conditions which are more precisely the same as during CS operation, a central solenoid insert sample (CSI) was tested in the external field of the Central Solenoid Model Coil (CSMC) Facility [17] shown in Fig. 14.

As the CSI is a single-layer solenoid, strain induced by the circular geometry (hoop strain) can be included in the evaluation of the CS conductor performance, which is not possible in the straight-line conductor samples in the SULTAN test. In addition, CSMC can generate an external field up to $13 \mathrm{~T}$. Thus, the purpose of the CSI test is to evaluate $T_{\text {cs }}$ under real CS operation (i.e., SOD conditions: $13 \mathrm{~T}$ of external field and $40 \mathrm{kA}$ of current) with hoop strain. An additional objective was to compare the results to the SULTAN tests. Therefore, the CSI tests also included the SULTAN conditions of $11.5 \mathrm{~T}$ of external field and $45 \mathrm{kA}$ of current. The requirement criteria for $T_{\mathrm{cs}}$ are $5.2 \mathrm{~K}$ and $6.5 \mathrm{~K}$ in the SOD and SULTAN conditions, respectively, as discussed above.

The result of the CSI test with SOD conditions is shown in Fig. 15. No degradation of $T_{\text {cs }}$ with increasing EM cycles was observed, and there was a temperature margin of at least $1.5 \mathrm{~K}$ above the $5.2 \mathrm{~K}$ of the requirement criterion. Thus, it can be assumed that even if 60,000 cycles of EM loading are imposed on the conductor, its performance will be sustained.

The CSI test result under SULTAN conditions is shown in Fig. 16. Again, no degradation of $T_{\text {cs }}$ was observed and there is a sufficient temperature margin above the $6.5 \mathrm{~K}$ criterion for SULTAN conditions. In addition, the $T_{\text {cs }}$ was about $0.5 \mathrm{~K}$ higher than the SULTAN test; this increase was the result of hoop strain. Thus, correlation between CSI and SULTAN tests was reasonable. This implies that the SULTAN test correctly represents the conductor performance.

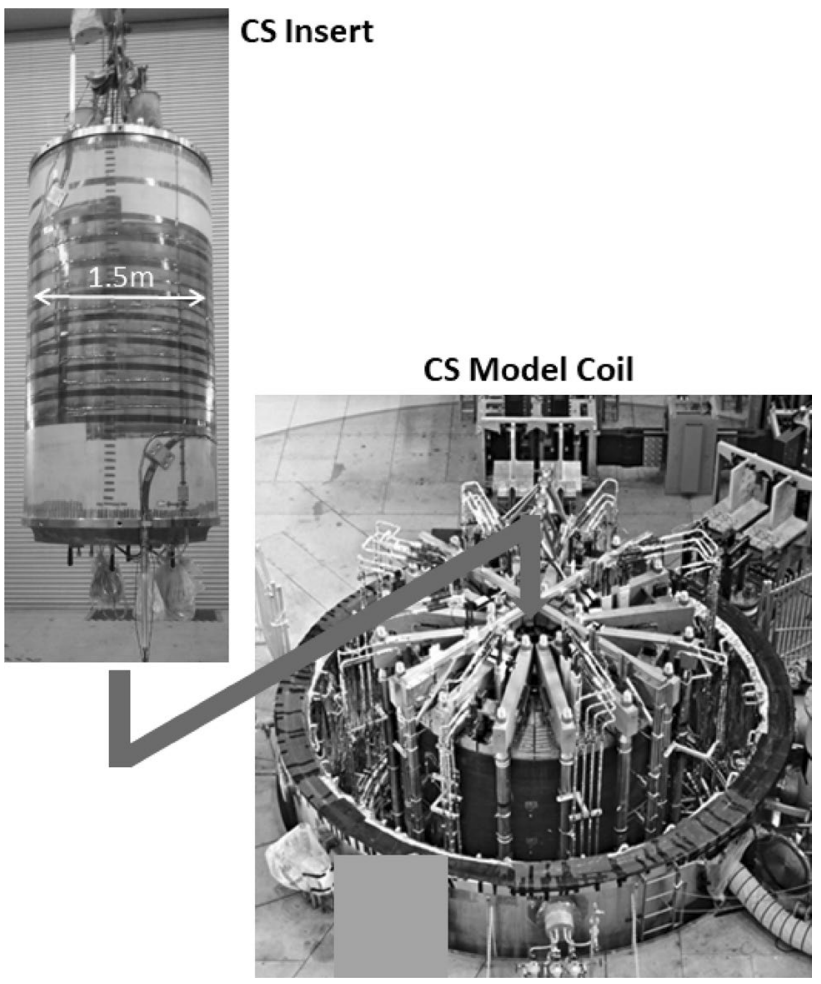

Fig. 14 Overview of the CS insert (CSI) test at the CS Model Coil Facility

\section{Conclusion}

Development of the CS conductor for ITER has given rise to technical challenges. However, QST overcame these difficulties with novel, accurate, and sophisticated investigation, notable consideration of the mechanisms degrading the current-sharing temperature and development of a

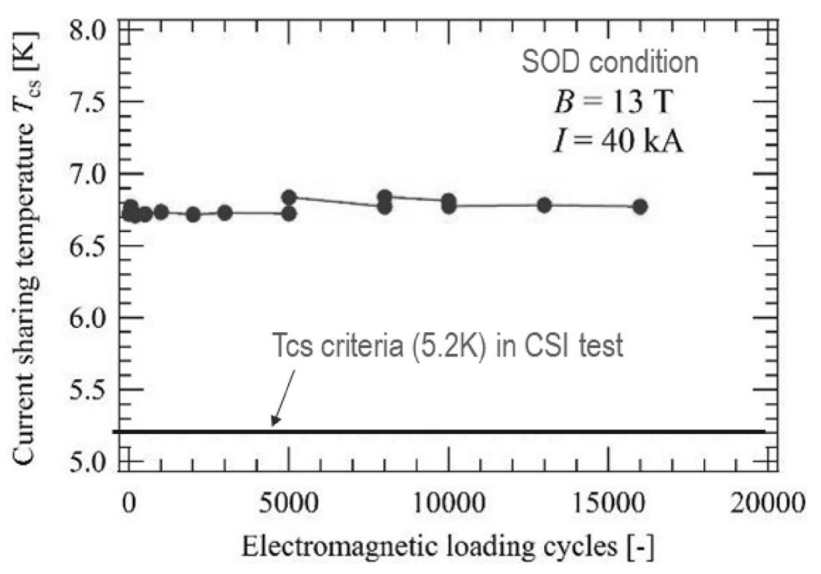

Fig. 15 Central solenoid insert (CSI) measurement of $T_{\text {cS }}$ under SOD conditions, as a function of EM cycles 


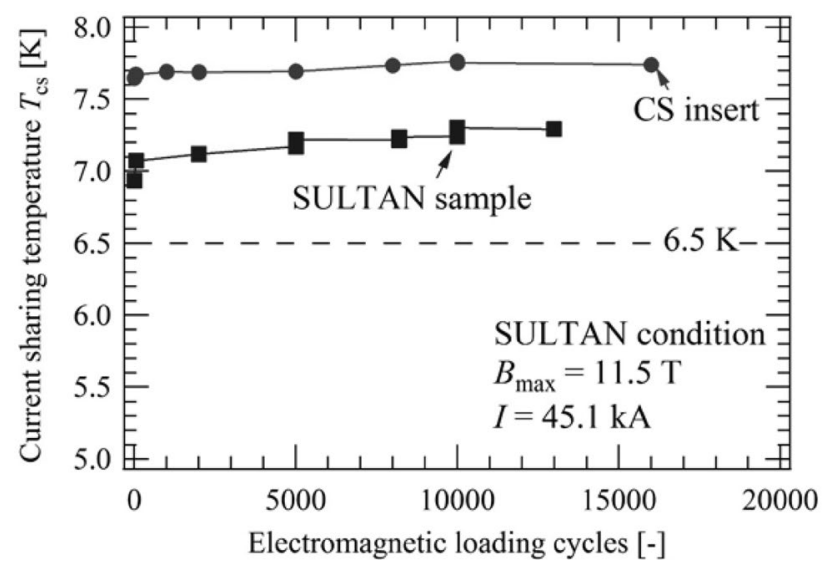

Fig. $16 \mathrm{CSI}$ measurement of $T_{\mathrm{cS}}$ under SULTAN conditions, as a function of EM cycles, in comparison with the SULTAN conductor test result

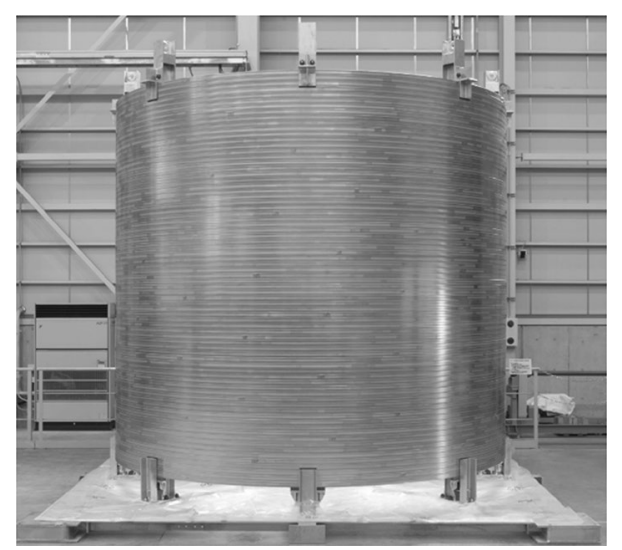

Fig. 17 Group photograph after fabrication of the final conductor

short twist pitch design for the CS conductor. Following this successful development stage, the series CS conductor production could be started in 2012. In parallel, a final check to qualify the conductor performance (CSI test) was conducted in 2015. Fabrication of all the CS conductors was successfully completed in 2017; the photograph of completion of the final conductor is presented in Fig. 17. CS conductors were shipped to the USA, which is a coil manufacturer of the CS. The last conductors finally arrived in March 2018.

\section{Compliance with ethical standards}

Conflict of interest The authors declare that they have no conflict of interest.

Human and animals rights No human participant and animal were involved in this study.

\section{References}

1. Hotkamp N (2007) An overview of the ITER project. Fusion Eng Des 82:427-434

2. Sborchia $C$ et al (2014) The ITER magnet systems: progress on construction. IAEA Nucl Fusion 54:013006

3. Mitchell $\mathrm{N}$ et al (2017) The ITER magnet system: configuration and construction status. Fusion Eng Des 123:17-25

4. Devred A et al (2012) Status of ITER conductor development and production. IEEE Trans Appl Supercond 22:4804909

5. Nabara $\mathrm{Y}$ et al (2013) Examination of $\mathrm{Nb}_{3} \mathrm{Sn}$ conductors for ITER central solenoids. IEEE Trans Appl Supercond 23(3):4801604

6. Nabara $Y$ et al (2016) Performance analysis of mass-produced $\mathrm{Nb}_{3} \mathrm{Sn}$ conductor for central solenoid in ITER. IEEE Trans Appl Supercond 26(3):4200705

7. Devred A et al (2013) Conductor qualification program for the ITER central solenoid. IEEE Trans Appl Supercond 23:6001208

8. Bruzzone P et al (2012) Test results of ITER conductors in the SULTAN facility. In: Proceedings of 24th IAEA Fusion Energy Conference IAEA CN-197, p 536

9. Hemmi T et al (2012) Test results and investigation of Tcs degradation in Japanese ITER CS conductor sample. IEEE Trans Appl Supercond 22:4803305

10. Hemmi T et al (2013) Neutron diffraction measurement of internal strain in the first Japanese ITER CS conductor sample. Supercond Sci Technol 26:084002

11. Bessette $\mathrm{D}$ (2014) Design of a $\mathrm{Nb}_{3} \mathrm{Sn}$ cable-in conduit conductor to withstand the 60,000 electromagnetic cycles of the ITER central solenoid. IEEE Trans Appl Supercond 24:4200505

12. Nijhus A (2011) Optimization of ITER $\mathrm{Nb}_{3} \mathrm{Sn} \mathrm{ClCCs}$ for coupling loss, transverse electromagnetic load and axial thermal contraction. Supercond Sci Technol 25:015007

13. Nabara $Y$ et al (2014) Impact of cable twist pitch on Tcs degradation and $\mathrm{AC}$ loss in $\mathrm{Nb}_{3} \mathrm{Sn}$ conductors for ITER central solenoids. IEEE Trans Appl Supercond 24:4200705

14. Takahashi $\mathrm{Y}$ et al (2014) Cabling technology of $\mathrm{Nb}_{3} \mathrm{Sn}$ conductor for ITER central solenoid. IEEE Trans Appl Supercond 4:4802404

15. Devred A et al (2014) Challenges and status of ITER conductor production. Supercond Sci Technol 27:044001

16. Martovetsky $\mathrm{N}$ et al (2016) ITER central solenoid insert test results. IEEE Trans Appl Supercond 26(4):4200605

17. Tsuji $\mathrm{H}$ et al (2001) ITER R\&D magnets: central solenoid model coil. Fusion Eng Des 55:153-170

18. Martovetsky N et al (2002) Test of the ITER central solenoid model coil and CS insert. IEEE Trans Appl Supercond 12:600-605

19. Bruzzone $P$ et al (2002) Upgrade of operating range for SULTAN test facility. IEEE Trans Appl Supercond 12:520-523

20. Nunoya $Y$ (2004) Experimental investigation on the effect of transverse electromagnetic force on the V-T Curve of the CIC conductor. IEEE Trans Appl Supercond 14(2):1468-1472

21. Koizumi N (2006) A new model to simulate critical current degradation of a large $\mathrm{CICC}$ by taking into account strand bending. IEEE Trans Appl Supercond 16(2):831-834

22. Sanabria $C$ et al (2012) Evidence that filament fracture occurs in an ITER toroidal field conductor after cyclic Lorentz force loading in SULTAN. Supercond Sci Technol 25:075007

23. Kajitani $\mathrm{H}$ et al (2013) Analytical study of degradation of $\mathrm{CIC}$ conductor performance due to strand bending and buckling. IEEE Trans Appl Supercond 23:2247652

Publisher's Note Springer Nature remains neutral with regard to jurisdictional claims in published maps and institutional affiliations. 